\title{
Cisplatin/Trastuzumab Regimen
}

National Cancer Institute

\section{Source}

National Cancer Institute. Cisplatin/Trastuzumab Regimen. NCI Thesaurus. Code C156366.

A chemotherapy regimen consisting of cisplatin and trastuzumab that may be used in the treatment of recurrent and metastatic HER-2 (EGFR2; ErbB2)-positive breast cancer. 